\title{
Akalazya tanısında yüksek çözünürlüklü manometri: 3. basamak referans merkez deneyimi
}

\section{High resolution manometry for diagnosis of achalasia: Tertiary reference center experience}

\author{
(D) Göktuğ ŞIRIN ${ }^{1}$, (D) Buğra Tolga KONDUK², (D) Seher ŞIRIN , D Altay ÇELEBì ${ }^{1}$ \\ Kocaeli Universitesi Tip Fakültesi, ${ }^{1}$ Gastroenteroloji Bilim Dah, ${ }^{3}$ Kulak Burun Boğaz Anabilim Dall, Ses Kliniği, Kocaeli \\ Gaziantep Universitesi Tip Fakültesi, ${ }^{2}$ Gastroenteroloji Bilim Dall, Gaziantep
}

\begin{abstract}
Giriş ve Amaç: Özofagusun etiyolojisi bilinmeyen primer motor bozukluğu olan akalazya, kesin tanısı motilite çalıșmalanı yapılarak konulan bir hastalıktır. Özofagogastrik bileşkede bulunan, maligniteye ya da geçirilmiş cerrahiye sekonder gelișen obstrüksiyon, hem klinik olarak, hem de manometrik ölçüm sonuçlanyla akalazyayı taklit edebilir. Çok sık rastlanan bir durum olmayan akalazyanın, ülkemizdeki epidemiyolojik özelliklerine ilişkin veriler son derece sinırlıdır. Güncel çalışmada, kliniğimizde takip edilen akalazyalı hastaların, epidemiyolojik özelliklerinin ve manometrik bulgularının incelenmesi amaçlanmıştır. Gereç ve Yöntem: Ekim 2017-Kasım 2019 tarihleri arasında, üniversitemiz gastroenteroloji bilim dalı motilite polikliniğinde tetkik edilen ve yüksek çözünürlüklü manometri sonuçlarına göre akalazya tanısı koyulan hastaların bilgi kartları, retrospektif olarak incelendi. Bulgular: Akalazya ön tanısıyla yüksek çözünürlüklü manometri yapılan 8 hastanın pseudoakalazya, 2 hastanın sekonder akalazya olduğu görüldü. Akalazya tanısı konulan 77 hastanın (43 erkek), yaş ortalaması $49.99 \pm 17.68$ (23-76) idi. Hastaların dörtte birinin 36 yaşından küçük, dörtte birinin 63.5 yaşından büyük olduğu görüldü. Hafifçe erkek baskın gibi görünen hasta grubunda, semptom başlangıcından tanı konuluncaya kadar geçen sürenin ortalama $4.43 \pm 4.05$ (1-20) yıl olduğu görüldü. Chicago Class 3.0 kriterlerine göre hastaların 35 tanesi (\%45.5) Tip 1; 39 tanesi (\%50.6) Tip 2; üç tanesi (\%3.9) ise Tip 3 akalazya tanısı almıştı. Özofagogastrik bileşke gevşemesinin değerlendirilmesi için kullanılan entegre gevşeme basıncı ortalama $22.81 \pm 11.44 \mathrm{~mm} \mathrm{Hg}$ ve alt özofagus istirahat basinc1 ise ortalama $31.96 \pm 18.74 \mathrm{~mm} \mathrm{Hg}$ idi. Tip 2 hastalarda entegre gevşeme basıncı ve ortalama alt özofagus istirahat basıncı Tip 1 hastalara göre, istatistiksel açıdan anlamlı olarak daha yüksek idi (sırasıyla, $p<0.001$ ve p<0.001). Sonuç: Akalazya hastalığının tanısı, günümüz teknolojisi ve bilgi birikimiyle sorun olmaktan çıkmış gibi gözükmektedir. Tanı ve tedavisi noktasında en büyük sorun, hastaların motilite çalışmalarına erişimine engel olan çeșitli bariyerlerdir. Tanı öncesi semptom süresinin uzun olmasında, özofagus motilite testlerinin gecikmeli olarak yapılması rol oynuyor olabilir. Bunu önlemek adına, disfajisi olan hastalar, özofagogastroskopik incelemeleri nor-
\end{abstract} mal bulunsa bile, muhakkak motilite testi yapılması için yönlendirilmelidir.

Anahtar kelimeler: Akalazya, özofagogastroskopi, yüksek çözünürlüklü manometri

\section{GİRISS}

Özofagusun etiyolojisi bilinmeyen primer motor bozukluğu olan akalazya, manometrik olarak alt özofagus sifinkterinin (AÖS) yetersiz gevşemesi ya da hiç gevşeyememesi ve özofagus gövdesinde peristaltizmin olmamasıyla, endoskopik olarak ise dilate bir özofagusta sindirilmemiş gıda artıklarının, tükürük, sıvı ve sekresyonların birikmesiyle karakterize, kesin tedavisi olmayan bir hastalıktır (1).
Background and Aims: Achalasia, which is a primary motor disorder with unknown etiology, is diagnosed using motility studies. Obstruction of the esophagogastric junction secondary to malignancy or previous surgery may mimic achalasia, both clinically and manometrically. Data related to the epidemiological characteristics of achalasia are minimal. This study investigated the epidemiological features and manometric findings of patients with achalasia who were followed up in our clinic. Material and Methods: Data of patients diagnosed with achalasia by using high resolution manometry between October 2017 and November 2019 were evaluated retrospectively. Results: Eight patients had pseudoachalasia, and two patients had secondary achalasia. The mean age of the 77 patients ( 43 male) diagnosed as true achalasia was $49.99 \pm 17.68$ years (23-76 years). One-fourth of the patients were younger than 36 years, and one-fourth were older than 63.5 years. The mean time from onset of symptom to diagnosis was $4.43 \pm 4.05$ years ( $1-20$ years) in the slightly male predominant patient group. According to Chicago Class 3.0 criteria, patients were diagnosed as Type 1, 2, and 3 achalasia in 35 (45.5\%), 39 (50.6\%), and $3(3.9 \%)$ study patients, respectively. The mean relaxation pressure used for the evaluation of esophagogastric junction relaxation was $22.81 \pm 11.44 \mathrm{mmHg}$, and the mean lower esophageal resting pressure was $31.96 \pm 18.74 \mathrm{mmHg}$. The mean relaxation pressure and mean lower esophageal resting pressure were significantly higher in Type 2 patients than Type 1 patients $(p<0.001$ and $p<0.001$, respectively). Discussion: The current technology facilitates the easy diagnosis of achalasia. However, the major problem in diagnosis and treatment is the various barriers that prevent patients from accessing motility studies. Delayed esophageal motility tests may cause prolonged pre-diagnosis symptoms. Patients with dysphagia should be referred for an esophageal motility test, even if their esophagogastroscopic examination is normal.

Keywords: Achalasia, esophagogastroscopy, high resolution manometry

Akalazya sık görülmeyen bir hastalık olup, yıllık insidansı 1:100.000 ve prevalansı 10:100.000 düzeyindedir. Kadın ve erkekler bu hastalığa eşit oranda yakalanırken, ırksal bir yatkınlık yoktur. Oluşumunda, otoimmünite, viral immünite ya da nörodejenerasyonun rol oynayabileceği düşünülmektedir $(1,2)$.
İletişim: Göktuğ ŞİRİN Kocaeli Üniversitesi Tıp Fakültesi, Gastroenteroloji Bilim Dalı, 41380, Kocaeli, Türkiye Tel: +9026230375 75 • Fax: +902623037003 Geliş Tarihi: 20.12.2019 Kabul Tarihi: 23.12.2019 
Özofagus motilitesindeki bozukluk, katı ve sıvı gıdalara karşı yutma güçlüğü ile ya da sindirilmemiş gıdaların ve birikmiş tükürügün regürjite olmasıyla kendini gösterebilir. Yutma güçlügü olup, yeterli doz ve süre boyunca verilen proton pompası inhibitörü (PPI) tedavisine yanıtsız regürjtasyonu olan hastalarda, akalazya varlığı sorgulanmalıdır.

Diğer yandan, özofagogastrik bileşkede bulunan obstrüksiyon, hem klinik olarak, hem de manometrik ölçüm sonuçlarıyla akalazyayı taklit edebilir. Gastrik kardiya tümörleri ya da miyenterik pleksusu infiltre eden gastroözofageal bileşke maligniteleri (Psödoakalazya), veya hastanın geçirmiş olduğu sıkı fundoplikasyon operasyonu ya da laparaskopik gastrik kelepçe uygulaması (sekonder akalazya) muhakkak sorgulanmalıdır $(3,4)$. Bu açıdan, ciddi ve akut kilo kaybı olmasının psödoakalazya için, cerrahi öyküsü bulunmasının ise sekonder akalazya açısından uyarıcı olabileceği unutulmamalı, akalazya tanısı konulması öncesinde mutlaka endoskopik ve manometrik inceleme yapılmalıdır.

Çok sık rastlanan bir durum olmayan akalazyanın, ülkemizdeki epidemiyolojik özelliklerine ilişkin veriler son derece sınırlıdır. Dünya çapındaki referans merkezlerinde yapılan çalışmalar bile, birkaç yüzü geçmeyen sayıda hastanın katılımiyla ve retrospektif dizaynda gerçekleştirilmektedir.

Bu nedenle, güncel çalışmada, kliniğimizde takip edilen akalazyalı hastaların, epidemiyolojik özelliklerinin ve manometrik bulgularının incelenmesi amaçlanmıştır.

\section{GEREÇ ve YÖNTEM}

Ekim 2017-Kasım 2019 tarihleri arasındaki iki ylllk dönemde, üniversitemiz gastroenteroloji bilim dalı motilite polikliniğinde tetkik edilen ve yüksek çözünürlüklü manometri (High resolüsyon manometri; HRM) yapılan hastalar, çalışmaya uygunluk açısından değerlendirildi. HRM sonuçlarına göre, akalazya tanısı koyulan 43'ü erkek, 34'ü kadın olmak üzere toplam 77 hastanın bilgi kartları, retrospektif olarak incelendi. Hastaların demografik ve epidemiyolojik özellikleri değerlendirildi. Hastaların başvuruya yol açan şikayetleri, semptomların başlangıç yaşı, tanının nasıl konulduğu, kullanmakta olduğu ilaçlar kayıt edildi. Tanı konulma zamanı, HRM yapılma zamanı olarak kabul edildi. Birden fazla kez HRM yapılan hastalarda, tanı konulan ilk inceleme verileri kullanıldı. Semptom başlangıcı ile tanı konulması arasında geçen zaman hesapland.

18 yaşından küçük olan, verilerinde eksiklik bulunan, takiplerinde pseudoakalazya tanısı alan veya özofagus-mide cerrahisi geçirme öyküsü olan hastalar, değerlendirme dışı bırakıld. Il içinden ya da dışından gelen, doğrudan başvuran veya refere edilen hastalar arasinda ayrim yapılmadı.

Özofagusun motor fonksiyonlarını etkileyebilecek ilaçlar (kalsiyum kanal blokerleri, nitratlar, antikolinerjikler vb.) manometrik incelemeden en az üç gün önce kesilmiş ve özofagusun manometrik incelemesi; 22 kanall, su bazll, HRM kullanılarak yapılmıştı. Yutmanın başlaması ve üst özofageal sfinkterin (ÜÖS) gevşemesinden, peristaltik kasılmanın distal özofagustaki ampullaya ulaşmasına kadar olan 10 saniyelik yutma penceresi içindeki en düşük basınçlı 4 saniyenin ortalama basıncı olarak rapor edilen, özofagogastrik bileşke gevşemesinin değerlendirilmesi için kullanılan, entegre gevşeme basincı (integrated relaxation pressure; IRP) ve her ne kadar Chicago klasifikasyonuna göre rapor edilmesi gerekli olmasa da, ortalama alt özofagus istirahat basınçları incelendi (5).

HRM sonuçları, Chicago Class 3.0 kriterlerine göre değerlendirilerek, akalazyanın alt tipleri belirlendi (6).

\section{İstatistiksel Analiz}

Tüm istatistiksel analizler, IBM SPSS Windows sürüm 20.0 (SPSS, Chicago, IL, ABD) kullanılarak yapıldı. Normallik varsayımını değerlendirmek için Kolmogorov-Smirnov testi kullanıldı. Sürekli değişkenler normal dağılıma bağlı olarak ya ortalama \pm standart sapma ya da (normal dağılım olmadığında) medyan (25-75.yüzdelik) ile sunuldu. Kategorik değişkenler sayı (yüzde) olarak özetlendi. Gruplar arasındaki sürekli değişkenlerin karşılaştırılması, hangisi uygunsa, bağımsız örnekler t testi / Mann Whitney U testi kullanılarak yapıldı. İki kategorik değişken arasındaki ilişki Ki-kare testi ile incelendi. Tüm istatistiksel analizler $\% 5$ anlamlllıkta yapıldı ve iki taraflı $\mathrm{p}$ değeri $<0.05$ olması istatistiksel olarak anlamlı kabul edildi.

Çalışma için etik kurul onayı, üniversitemiz lokal etik kurulundan alındı.

\section{BULGULAR}

Çalışma süresi boyunca toplam 92 HRM işlemi yapılmış idi. Işlemin 3 hastaya 2'şer kez, diğer hastalara ise birer defa yapıldığı görüldü. On iki işlem, çalışma kriterlerine uymadığı için değerlendirme dışı bırakıldı (Tablo 1). HRM ile akalazya tanısı konulan 77 hastanın (43 E, 34 K), yaşlarının 23 ile 76 arasında değişmekte olduğu görüldü. Yaş ortalaması, tüm hasta grubu için 49.99 17.68 idi. Hastaların dörtte birinin 36 yaşından küçük, dörtte birinin 63.5 yaşından büyük olduğu görüldü. Hastaların geri kalan yarısı ise, 36-63.5 yaş aralığında yer almakta idi. Hafifçe erkek baskın gibi görünen hasta grubunun demografik özellikleri ve manometri bulguları Tablo l'de gösterildi. Semptom başlangıcı, dosyasında açıkça tarif edilen 54 hastanın verileri üzerinden yapılan değerlendirmede, tanı konuluncaya kadar geçen sürenin ortalama $4.43 \pm 4.05$ (1-20) yll olduğu görüldü (Tablo 1). 50 yaşından büyük hastalarda, sürenin uzama eğiliminde olması dikkati çekti. 


\section{Tablo 1. Çalışma hastalarının demografik özellikleri ve manometri bulguları}

HRM Yapılan Hasta /HRM İşlem Sayısı (n/n)

Değerlendirme dışı kalan hasta sayısı (n)

Çalışma grubundaki hasta sayısı (n)

Cinsiyet (E/K)

Yaş

Akalazya Tip (1/2/3) $(\mathrm{n}=77)$

Ortalama AÖS basıncı $(\mathrm{mmHg})$

Ortalama IRP $(\mathrm{mmHg})$

Semptom süresi (yıl)

\section{9/92*}

$12 * *$

(pseudo-akalazya tanılı 8 hasta; sekonder akalazya tanılı 2 hasta; 18 yaş altı 2 hasta)

77

$43 / 34$

$49.99 \pm 17.68$

$35 / 39 / 3$

$31.96 \pm 18.74$

$22.81 \pm 11.44$

$4.43 \pm 4.05$

*3 hastaya iki kez HRM yapıldı. **HRM sonuçları değerlendirme dıșı kalan hastalar.

E: Erkek; K: Kadın; AÖS: Alt özofagus sfinkter; IRP: Entegre gevșeme basıncı.

\section{Tablo 2. Demografik özelliklerin ve HRM parametrelerinin akalazya tipleri ile ilişkisi*}

$\begin{array}{lccc} & \text { Tip 1 (n=35) } & \text { Tip 2 (n=39) } & \text { P değeri } \\ \text { Yaş } & 47.71 \pm 17.52 & 51.62 \pm 17.98 & 0.349 \\ \text { Ortalama AÖS-B (mmHg) } & 20.00(18.00-24.00) & 34.00(24.00-54.00) & <\mathbf{0 0 1} \\ \text { IRP (mmHg) } & 15.00(15.00-17.00) & 22.00(18.00-31.00) & <\mathbf{0 0 1} \\ \text { Semptom süresi } & 3.00(1.00-5.00) & 3.00(2.00-8.00) & 0.263 \\ \text { Cinsiyet } & & & \\ \text { E } & 15(\% 42.9) & 18(\% 46.2) & 0.960 \\ \text { K } & 20(\% 57.1) & 21(\% 53.8) & \end{array}$

*: Tip 3 hastalar, sayıları çok az olduğu için $(n=3)$ değerlendirme dışı bırakılmıştır. AÖS-B: Alt özofagus sfinkter basıncı; IRP: Entegre gevşeme basıncı; HRM: Yüksek çözünürlüklü manometri.

Bütün hastalara özofago-gastroduodenoskopi ve yüksek çözünürlüklü manometri incelemesi yapılmıştı. HRM kullanılarak yapılan manometrik inceleme sonuçları, Chicago Class 3.0 kriterlerine göre değerlendirilmiş ve hastaların 35 tanesi (\%45.5) Tip 1; 39 tanesi (\%50.6) Tip 2; üç tanesi (\%3.9) ise Tip 3 akalazya tanısı almıştı. Özofagogastrik bileşke gevşemesinin değerlendirilmesi için kullanılan entegre gevşeme basıncı (IRP) ortalama $22.81 \pm 11.44 \mathrm{mmHg}$ ve alt özofagus istirahat basincı ise ortalama $31.96 \pm 18.74 \mathrm{mmHg}$ idi.

Tip 3 olan hasta sayısı çok az olduğu için (n=3), istatistiksel analizlerde kullanılmadi. Tip 2 hastalarda IRP ve ortalama alt özofagus istirahat basıncı, Tip 1 hastalara göre, istatistiksel açıdan anlamlı olarak daha yüksek idi (sırasıyla, $\mathrm{p}<0.001$ ve $\mathrm{p}<0.001$ ). Bu basınçlar ve akalazya tipleriyle ilişkisi Tablo 2'de özetlendi.

\section{TARTIŞMA}

Çok sık görülmeyen bir hastalık olan akalazyanın tanısı için, günümüzde konvansiyonel manometri yerine, HRM kullanılmaktadır (7). Nitekim bir çalışmada, HRM'nin akalazya tanısinda konvansiyonel manometriye göre 2 kat üstün (\%12 vs
\%26) olduğu gösterilmiştir (8). HRM, intraluminal basınc1, özofagus gövdesinde 36 cm'lik segment boyunca, 1 cm'lik aralıklarla çepeçevre kaydeder. Bu şekilde elde edilen basınç ölçümleri, renkli topografik şekil grafiklerine dönüştürülür. Bu dönüşüm, uygulama açısından kolaylık yaratır ve renkli şekil paternlerinin yorumlanması çok daha kolay olur. Tip 1 ve Tip 2 akalazya tanılı iki ayrı hastamıza ait HRM resimleri, sirasiyla Resim 1 ve 2'de gösterilmektedir.

Akalazyanın alt tiplerini ayırt etme konusunda, hem değerlendiriciler arasında hem de değerlendiricilerin kendi içinde hemfikir olma (inter-rateragreement, intra-rateragreement) oranı mükemmele yakın olan Chicago sınıflaması (CC v3.0), HRM çalışmalarını yorumlamayı ve özofagus motilite bozukluklarını sınıflandırmayı sağlayan bir uygulamadır $(6,9,10)$. Bu sinıflamada HRM'nin getirdiği yeni bazı ölçütler kullanılmaktadır. Bu ölçütlerden biri de IRP'dir ve özofagogastrik bileşke gevşemesinin değerlendirilmesi için kullanılır. Bir çalışmada IRP cut-off değeri 15 olarak alındığında, akalazyanın tespitinde \%98 sensitiviteye ve \%96 spesifiteye sahip olduğu gösterilmiştir (IRP cut-off değerinin kullanılan katetere göre değişebileceği unutulmamalıdır) (11). Bu üstünlügünden dolayı çalışmamızda HRM kullanılmıştır. 


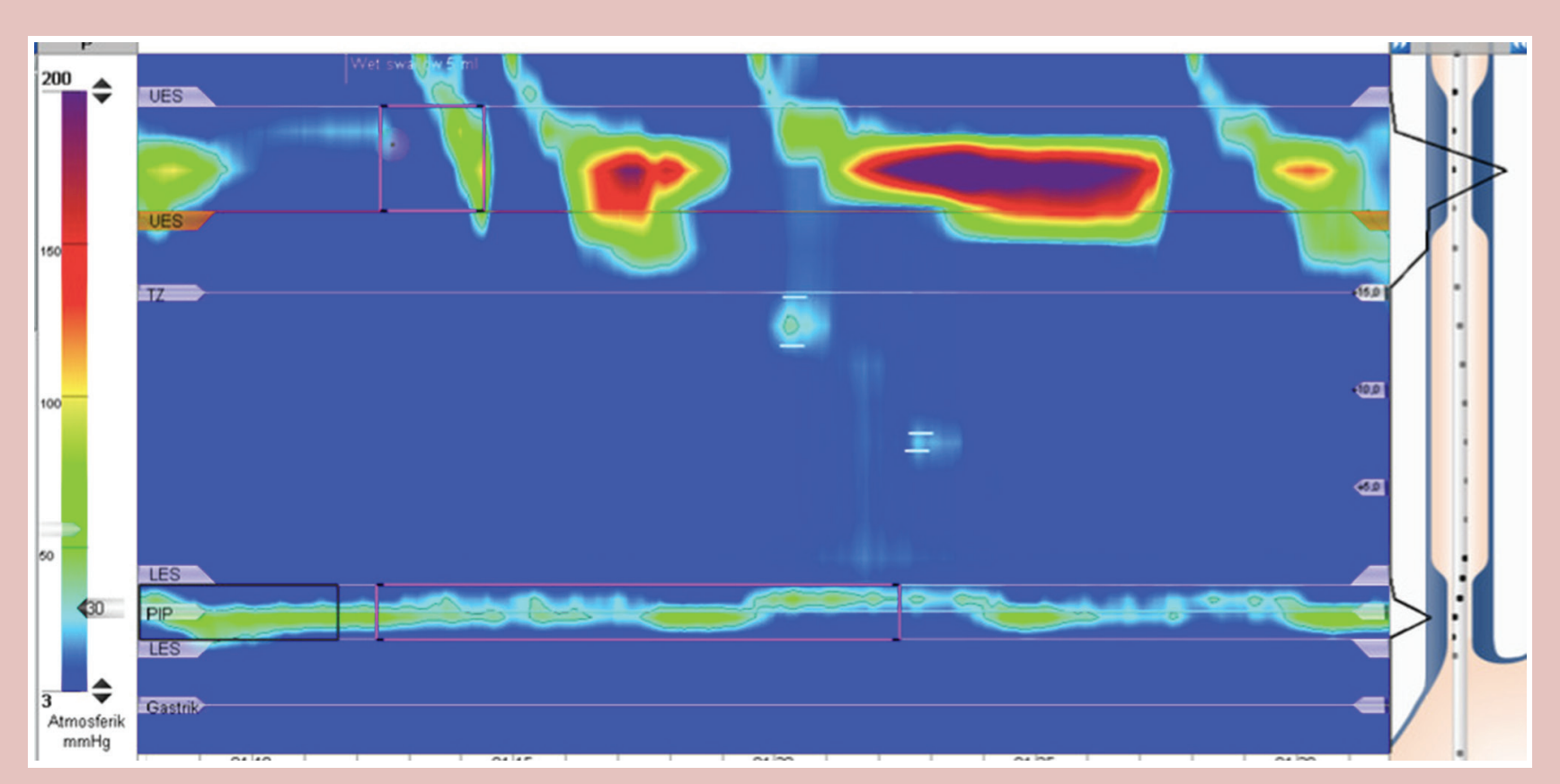

Resim 1. Tip 1 akalazya tanılı hastamıza ait HRM görüntüsü.

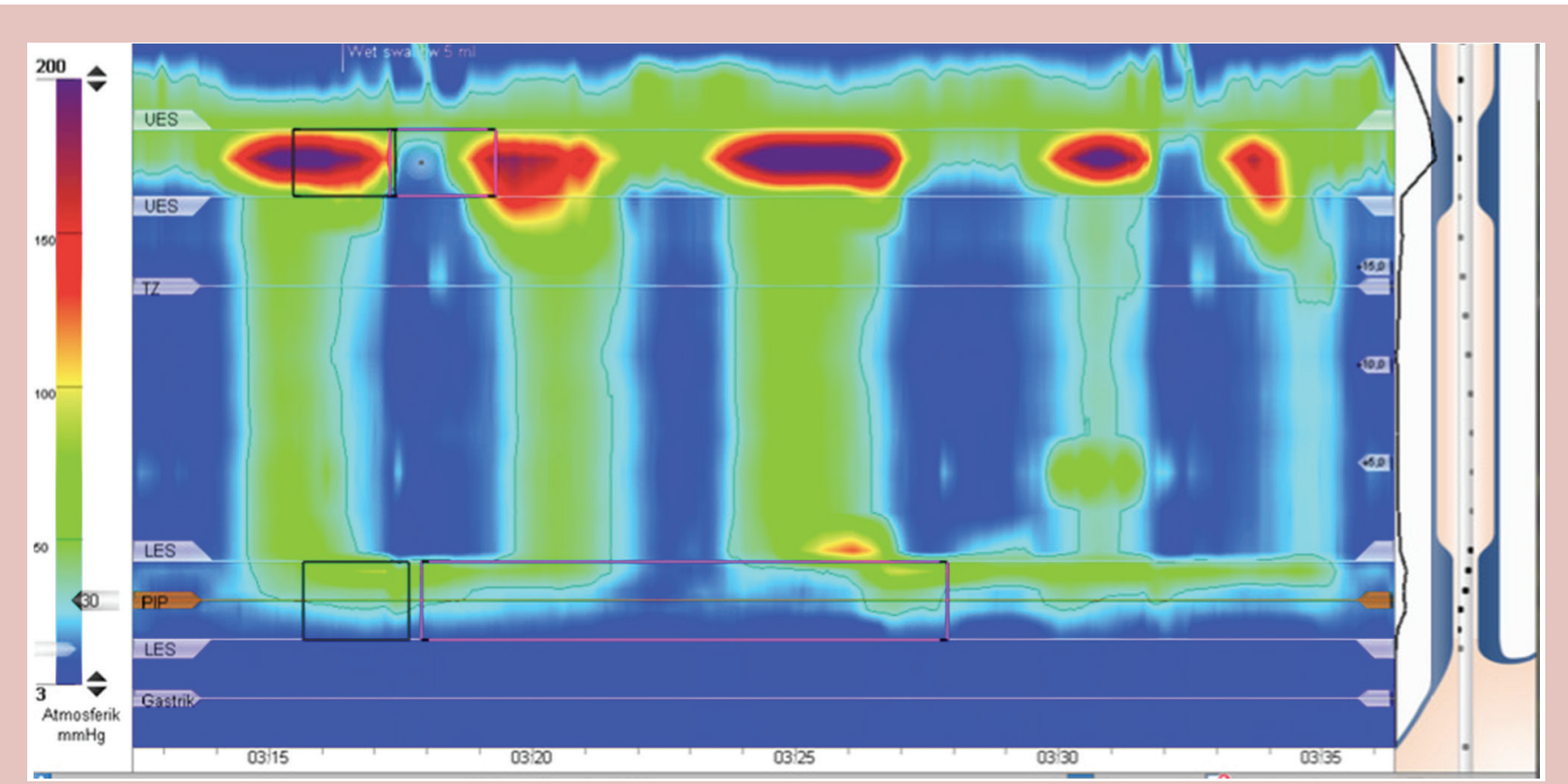

Resim 2. Tip 2 akalazya tanılı hastamıza ait HRM görüntüsü.

Epidemiyolojisi hakkında yapılmış birçok çalışmada, akalazyanın, çevresel faktörlerin etkin olduğunu düşündürür tarzda, erkek bireylerde ve 50 yaş üzerinde çok daha sık tespit edildiğine vurgu yapılmaktadır (12-14). Yaş ilişkili bu paternin, nöron dejenerasyonu ve nöronal kontrolün artan yaşa bağlı kaybı sonucu oluşabileceği düşünülmektedir. Bu durum, özel- likle yaşlı hasta grubunda, motilite çalışmalarının yapılmasına olan gönülsüzlük nedeniyle, akalazya dişı motilite bozuklukları ve nonspesifik özofagus motor anormalliklerinin tümüne akalazya tanısı konulmasının bir sonucu da olabilir. Bu zorluğun HRM'nin kullanıma girmesiyle çok azalmasına rağmen, kısmen günümüzde de geçerliliğini koruyor olması mümkündür. 
Öte yandan, elli yaş üzeri grupta artmış insidansın, hastalığın tespit edilmesinin gecikmesine bağlı olma ihtimali de göz önünde bulundurulmalıdır. Belki eskiden geçerli olabilecek bu durum, özellikle HRM ve Chicago klasifikasyonunun kullanıma girmesiyle, artık geçerliliğini kaybetmiş durumdadır. Nitekim, HRM kullanılarak akalazya tanısı konulmuş çalışma grubumuzda, hastalarımızın yaklaşık yarısı 36-63.5 yaş aralığında olup, bu anlamda literatürden farklllık göstermektedir.

Hastalığın nadir görülmesi nedeniyle, çok az sayıda ve çoğu kısıtlı hasta sayısı ile gerçekleştirilmiş epidemiyolojik çalışmalar bulunmaktadır. Çok az sayıda çalışmada, hasta sayısı 150 üzerindedir (15-18). Güncel çalışmadaki hasta sayısı, literatürdeki çoğu çalışma ile benzer düzeydedir.

Literatürdeki birçok çalışmaya benzer şekilde, çalışmamızda, erkek cinsiyet biraz daha sık tutulmuş gibi görünmekle birlikte, cinsiyet farkının çok belirgin olmadığı (E/K:1.26) söylenilebilir. Ortalama tanı yaşının da, literatür ile benzer olduğu görülmüştür (15,19-22).

Tanı anındaki ortanca semptom süresi literatüre benzer olup, çoğu çalışma uzun süreli semptom varlığına işaret etmektedir. Bin iki yüz hastayı inceleyen toplam 12 çalışmanın sonuçları incelendiğinde, ortalama semptom süresinin 4.6 yl olduğu görülmüştür (23). Bizim çalışmamızda ise bu süre $4.43 \pm 4.05$ yll olarak tespit edilmiştir. Diğer yandan, semptom süresi çok geniş sinırlar içerisinde belirgin farklllıklar gösterebilmektedir. Bizim çalışmamızda bu sınırlar 1-20 yıl aralı̆̆ında iken, literatürde, semptomların başlangıcından tanı anına kadar 30 hatta 40 yll geçmiş vakalar olduğu bildirilmektedir. Semptom süresindeki bu keskin farklılığın altında yatan pek çok sebep olabilir. Medikal bakıma erişimde, yaşlı hastaların tedaviye eşit ulaşımında ya da bakım maliyetlerinde yaşanan sorunlar, hastanın tıbbi yardım isteme eşiğindeki farklılıklar, bunlar arasında sayılabilir. Ancak özellikle ülkemizde, hastaların özofagus manometri tetkiki yapılması için yönlendirilmele- rinde gecikme olmasıyla da ilişkili olabilir. Çalışmamız bunu değerlendirmeye yönelik olarak dizayn edilmemiş olmakla birlikte, akalazya tanısı alan birçok hastamızın psikiyatriye gönderildiği ve halihazırda antidepresan ya da anksiyolitik ilaç kullanmakta olduğu görülmüştür. Bu yüzden, disfajisi olan hastanın özofagogastroskopik incelemesi normal bulunduğunda, gastroenterologların hastayı psikiyatriye yollamadan önce, muhakkak motilite testi yaptırması gerektiği vurgulanmalıdır.

Akalazyanın en sık görülen formu Tip 2'dir. Nitekim, güncel çalışmamızda da hastalarımızın \%50.6'sının (39/77) Tip 2 akalazya olduğu tespit edildi. Sadece, üç adet hasta Tip 3 olduğu için, istatistiksel çalışmalarda kullanılmadı. Tip 1 ve 2 arasında yapılan karşılaştırmada, IRP ve alt özofagus istirahat basıncının, Tip 2 hastalarında istatistiksel açıdan anlamlı düzeyde daha fazla olduğu görüldü. Bu durumun, Tip 2 akalazyada kasılma gücünün daha fazla olması ile açıklanabileceği düşünüldü. Cinsiyet, yaş veya semptom süresi açısından yapılan karşılaştırmada ise gruplar arasında herhangi bir farklılık izlenmedi (Tablo 2).

Çalışmamızın retrospektif dizaynı en büyük eksikliği olmakla birlikte, ayrım gözetmeksizin, çalışmaya katılan tüm hastaların tek bir referans merkezde değerlendirilmiş olması ve literatürdeki diğer çalışmalar ile kıyaslanabilecek hasta sayısı nedeniyle, elde ettiği epidemiyolojik ve manometrik verilerin önemli olduğuna inanıyoruz.

Sonuç olarak, sık görülmediği için, kimi zaman yok sayılma tehlikesi bulunan akalazya hastalı̆̆ının tanısı, günümüz teknolojisi ve bilgi birikimiyle sorun olmaktan çıkmış gibi gözükmektedir. Tanı ve tedavisi noktasında en büyük sorun, hastaların motilite çalışmalarına erişimine engel olan çeşitli bariyerlerdir. Bu engellerin aşılması için, farkındalığın arttırılması ve gerektiğinde yeni teknolojilerin daha erken ve daha sık kullanılması uygun olacaktır.

\section{KAYNAKLAR}

1. Vaezi MF, Pandolfino JE,Vela MF. ACG clinical guideline: diagnosis and management of achalasia. Am J Gastroenterol 2013;108:1238-49, quiz 1250 .

2. Francis DL, Katzk DA. Achalasia: update on the disease and its treatment. Gastroenterology 2010;139:369-74.

3. Tucker HJ, SnapeWJ Jr, Cohen S. Achalasia secondary to carcinoma: manometric and clinical features. Ann Intern Med 1978;89:315-8.

4. Rozman RW Jr, Achkar E. Features distinguishing secondary achalasia from primary achalasia. Am J Gastroenterol 1990;85:1327-30.

5. Pandolfino JE, Fox MR, Bredenoord AJ, Kahrilas PJ. High resolution manometry in clinical practice: utilizing pressure topography to classify oesophageal motility abnormalities. Neurogastroenterol Motil 2009;21:796-806.

6. Kahrilas PJ, Bredenoord AJ, Fox M, et al; International High Resolution Manometry Working Group. The Chicago Classification of esophageal motility disorders, v3.0. Neurogastroenterol Motil 2015;27:160-74.

7. Zaninotto G, Bennett C, Boeckxstaens G, et al. The 2018 ISDE achalasia guidelines. Dis Esophagus 2018;31:1-29.

8. Roman S, Huot L, Zerbib F, et al. High-resolution manometry improves the diagnosis of esophageal motility disorders in patients with dysphagia: a randomized multicenter study. Am J Gastroenterol 2016;111:372-80.

9. Richter JE. High-resolution manometry in diagnosis and treatment of achalasia: help or hype. Curr Gastroenterol Rep 2014;16:420.

10. Carlson DA, LinZ, Kahrilas PJ, et al. The functional lumen imaging probe detects esophageal contractility not observed with manometry in patients with achalasia. Gastroenterology 2015;149:1742-51.

11. Ghosh SK, Pandolfino JE, Rice J, et al. Impaired deglutitive EGJ relaxation in clinical esophageal manometry: a quantitative analysis of 400 patients and 75 controls. Am J Physiol Gastrointest Liver Physiol 2007;293:878-85

12. Mayberry JF, Atkinson M. Studies of incidence and prevalence of achalasia in the Nottingham area. Q J Med 1985;56:451-6. 
13. Sonnenberg A, Massey BT, McCarty DJ, Jacobsen SJ. Epidemiology of hospitalization for achalasia in the United States. Dig Dis Sci 1993;38:233-44.

14. Farrukh A, DeCaestecker J, Mayberry JF. An epidemiological study of achalasia among the South Asian population of Leicester, 1986-2005. Dysphagia 2008;23:161-4.

15. Arber N, Grossman A, Lurie B, et al. Epidemiology of achalasia in central Israel. Rarity of esophageal cancer. Dig Dis Sci 1993;38:1920-5.

16. Mayberry JF, Atkinson M. Variations in the prevalence of achalasia in Great Britain and Ireland: an epidemiological study based on hospital admission. Q J Med 1987;62:67-74.

17. Mayberry JF, Atkinson M. Incidence of achalasia in New Zealand, 198084: an epidemiologic study based on hospital discharges. J Gastroenterol Hepatol 1988;3:247-52.
18. Sonnenberg A. Hospitalization for achalasia in the United States 19972006. Dig Dis Sci 2009;54:1680-5.

19. Earlam RJ, Ellis FH Jr, Nobrega FT. Achalasia of the esophagus in a small urban community. Mayo Clin Proc 1969;44:478-83.

20. Ho KY, Tay HH, Kang JY. A prospective study of the clinical features, manometric findings, incidence and prevalence of achalasia in Singapore. J Gastroenterol Hepatol 1999;14:791-5.

21. Howard PJ, Maher L, Pryde A, Cameron EW, Heading RC. Five year prospective study of the incidence, clinical features, and diagnosis of achalasia in Edinburgh. Gut 1992;33:1011-5.

22. Mayberry JF, Rhodes J. Achalasia in the city of Cardiff from 1926 to 1977. Digestion 1980;20:248-52.

23. Birgisson S, Richter JE. Achalasia: what's new in diagnosis and treatment? Dig Dis 1997;15(Suppl 1):1-27. 